\title{
Management of cardiac manifestations in Takayasu arteritis
}

\author{
Mohammed Idhrees', Nambi Thilagavathi ${ }^{1,2}$, Mohamad Bashir ${ }^{3}$, Bashi V. Velayudhan ${ }^{1}$ \\ 'Institute of Cardiac and Aortic Disorders, SIMS Hospital, Chennai 600026, India. \\ ${ }^{2}$ Consultant, Department of Rheumatology, SIMS Hospital, Chennai 600026, India. \\ ${ }^{3}$ Department of Vascular \& Endovascular Surgery, Royal Blackburn Teaching Hospital, Blackburn BB2 3HH, United Kingdom.
}

Correspondence to: Dr. Mohammed Idhrees, Cardiovascular Surgeon, Institute of Cardiac and Aortic Disorders, SRM Institutes for Medical Science (SIMS Hospital),Chennai 600026, India. E-mail: a.m.idhrees@gmail.com

How to cite this article: Idhrees M, Thilagavathi N, Bashir M, Velayudhan BV. Management of cardiac manifestations in Takayasu arteritis. Vesse/ Plus 2020;4:23. http://dx.doi.org/10.20517/2574-1209.2020.15

\author{
Received: 11 May 2020 First Decision: 22 Jun 2020 Revised: 7 Jul 2020 Accepted: 10 Jul 2020 Published: 15 Aug 2020 \\ Academic Editor: Cristiano Spadaccio Copy Editor: Cai-Hong Wang Production Editor: Jing Yu
}

\begin{abstract}
Takayasu arteritis (TA) is a chronic vasculitis involving large vessels of unknown aetiology, a disease that is more common among the Asian population and predominant in young women. Cardiac manifestations include hypertension and involvement of the cardiac valves, myocardium and coronary arteries. Surgery on these patients is always a challenge given the tissue quality and the disease activity. They are prone to long-term complications such as restenosis and graft occlusion, hence requiring lifelong surveillance. The prevalence of coronary artery disease (CAD) in TA ranges from 9 to 11\%. Coronary artery bypass grafting is preferred to percutaneous coronary intervention, as the latter has a high rate of restenosis and major adverse cardiovascular events. As left subclavian artery is commonly involved, saphenous vein graft is advised as a conduit rather than internal mammary artery. Other surgical procedures described for CAD are surgical angioplasty of the left main coronary artery and transaortic coronary ostial endarterectomy. Aortic regurgitation in TA has an incidence of approximately $20 \%$. These patients tend to have prosthetic valve detachment, paravalvular leak or pseudoaneurysm at the anastomotic site. Further repair of these valves have a high rate of failure. Considering these facts, it is advisable to do an aortic root replacement for TA patients than to consider an aortic valve replacement or David's procedure.
\end{abstract}

Keywords: Takayasu arteritis, coronary artery, aortic valve, myocarditis, ascending aorta, aortoarteritis, pulmonary arteritis 


\section{INTRODUCTION}

Takayasu arteritis (TA) is a chronic vasculitis involving large vessels. It mainly involves the aorta and its branches, pulmonary artery and coronary artery. Though the cause of TA is unclear, there is a strong association with genetic predisposition, environmental factors and role of microbes. The arterial wall hosts the pathogenic activated $\mathrm{T}$ lymphocytes and macrophages leading to granulomatous inflammation and ultimately vessel wall damage. Proinflammatory cytokines, namely interleukin-6 (IL-6) and tumor necrosis factor- $\alpha$ (TNF- $\alpha$ ), are elevated in TA, which correlates with disease activity ${ }^{[1]}$. It is more common among young women and the Asian population. Recent surveys show that TA is increasing in prevalence among all ethnicities. In this review, we will discuss the management of the cardiac manifestations in TA myocardial failure, pulmonary arteritis and involvement of coronary artery and aortic valve.

\section{EPIDEMOLOGY}

TA is rare, but most commonly seen in the Asian population and immigrant Asian population in Western countries. The prevalence of TA in Scandinavian countries has increased, probably because of the higher rates of immigration from Asia and Africa in the last decade ${ }^{[2]}$. The incidence and prevalence of TA in the northwestern part of Turkey is similar to that of Japan. Norway and Sweden has reported higher a prevalence rate of TA than previously observed ${ }^{[3,4]}$. The disease has a predilection for females with wide geographic variation ranging from 8:1 in Japan to 1.2:1 in Israel. In a recent Japanese study, females less than 40 years of age constituted a major proportion $(83.8 \%)$ of the study cohort. The disease is five times more common in females than men, and an interesting feature reported in the study was that there was a larger proportion of elderly compared to a previous study ${ }^{[5]}$. TA presents commonly in the second and third decades of life. In women, the disease peaks at 20 years of age ${ }^{[6]}$. There are geographic variations of the involvement of the aorta and its branch vessels.

\section{GENETIC PREDISPOSITION}

The pathogenesis of TA has been associated with the human leukocyte antigen (HLA) class I (HLA-A, HLA-B, and HLA-C), HLA class II (HLA-DR, HLA-DQ, and HLA-DP) and non-HLA genes ${ }^{[7]}$. Though an elaborate list of genes exists in literature, a few are shown in Table $1^{[7,8]}$. There is definite HLA B52 allele association in TA beyond ethnicity ${ }^{[1]}$. The correlation with TNF- $\alpha 308 / \mathrm{G}$ polymorphism has also been reported in TA. FCGR2A/FCGR3A, IL-12B, IL-6, RPS9/LILRB3 are the non-HLA loci related to TA. A report from Italy demonstrated an association with HLA DRB1 ${ }^{\star} 0405$ for early onset vasculitis ${ }^{[8]}$. DRB1, DR2, DQ 1 are among other alleles related to TA.

\section{DIAGNOSIS AND MANAGEMENT}

\section{Clinical presentation}

Symptoms such as fever, weight loss, malaise, fatigue and myalgia due to systemic inflammatory reactions constitute the initial presentation of the disease. The inflammation of the carotid artery can cause carotidynia. Patients with vascular compromise may present with features of claudication pain, angina pectoris, transient ischemia attack and stroke. It is important to note that TA patients can be asymptomatic with underlying progressive disease ${ }^{[9]}$. The appearance of a new vascular sign in patients such as femoral bruits, absent pulses, or blood pressure differences should alert the physician. Usually, vascular signs are late manifestations of TA, but they can be the presenting symptom of a patient. The specificity and sensitivity of these clinical signs are more than $90 \%$ when two abnormal findings are present and not when a pair of examination findings is present ${ }^{[10]}$. In a series from Japan, the commonest complication was systemic hypertension followed by aortic regurgitation (AR). The complications were more common in men and patients with late referrals ${ }^{[5]}$. 
Table 1. Associations between Takayasu arteritis and HLA and non-HLA alleles/loci

\begin{tabular}{|c|c|c|c|}
\hline & Alleles/loci & Observed population & Type of association with TA \\
\hline \multirow[t]{8}{*}{ HLA class I } & $A(A 10)$ & Japan & Possible protective role \\
\hline & B39 & Japan, Mexico & Susceptibility, linked to B52 \\
\hline & B5 & Japan, India & \\
\hline & B51 & Japan, India, Turkey & Susceptibility (weak) \\
\hline & $\mathrm{B} 52^{\star} 01$ & $\begin{array}{l}\text { Japan, China, North America, Turkey, } \\
\text { India, Mexico }\end{array}$ & $\begin{array}{l}\text { Susceptibility (strong), severe disease, poor } \\
\text { prognosis }\end{array}$ \\
\hline & B67 & Japan & Susceptibility (weak) \\
\hline & $\mathrm{Cw}^{\star} \mathrm{O} 7$ & Europe, America, Turkey & Possible protective role \\
\hline & $\mathrm{Cw}^{\star} 12$ & Europe, America, Asia & Susceptibility \\
\hline \multirow[t]{8}{*}{ HLA class II } & $\mathrm{DRB}^{\star}{ }^{\star} 0405$ & North America, Europe & Susceptibility, early-onset disease \\
\hline & $\mathrm{DRB} 1^{\star} 07$ & Japan, China & Susceptibility \\
\hline & DPB1*09 & China & Susceptibility \\
\hline & DQw1 & Japan & Susceptibility \\
\hline & DQw2 & Korea & Susceptibility (weak) \\
\hline & DR2 & Japan & Susceptibility \\
\hline & DR7 & Korea & Susceptibility (weak) \\
\hline & $\mathrm{DRB} 1^{\star} 07$ & China & Susceptibility \\
\hline \multirow[t]{4}{*}{ non-HLA } & IL6 & America, Turkey & Susceptibility \\
\hline & RSP9/LILRB3 & America, Turkey & susceptibility \\
\hline & IL12B & Japan & susceptibility, possible resistance to therapy \\
\hline & TNFa 308A/G polymorphism & Japan, China & susceptibility \\
\hline
\end{tabular}

HLA: human leukocyte antigen; TA: Takayasu arteritis; IL: interleukin; TNF: tumor necrosis factor

\section{Laboratory findings}

Pentraxin 3 is produced in the inflammatory region by dendritic cells, vascular smooth muscle cells, fibroblasts and macrophages through the trigger of proinflammatory cytokines, especially TNF- $\alpha$. The levels are raised in TA and have a better specificity and sensitivity in delineating active and inactive disease ${ }^{[6,11,12]}$. Interleukins, such as IL- 6 and IL-8, IL-18, BAFF and anti-endothelial and anti-aorta antibodies are correlated with disease activity in $\mathrm{TA}^{[13]}$. Serum amyloid $\mathrm{A}$ is an acute phase protein produced in response to proinflammatory cytokines by activated macrophages. Serum amyloid A levels are significantly raised in patients with active disease $e^{[6,14]}$. When there is vessel wall inflammation, HLA E is released from the endothelium in the soluble form. sHLA E can also be used as a marker of activity of $\mathrm{TA}^{[15]}$. The acute phase reactants (ESR and CRP) though used to track disease activity, lack sensitivity and specificity. A study from the Cleveland Clinic showed 23\% of patients with normal acute phase reactants in the setting of active disease $^{[16]}$. Another analysis from North America showed elevated acute phase reactants in $44 \%$ of patients who were considered to be clinically inactive. Furthermore, ESR was elevated in only three-fourths of the patients who had active disease ${ }^{[17]}$.

\section{Imaging in TA}

The majority of Ishikawa diagnostic criteria for TA are dependent on imaging studies. The available imaging modalities lack specificity for disease activity, which emphasizes the complementary role of physical examination and laboratory investigation in assessment of disease activity. The relative advantages and disadvantages of each imaging modality are described in Table $2^{[18]}$. Lack of specificity for disease activity in available imaging tests highlights the complementary role of imaging in clinical assessment of disease activity. Historically, TA diagnosis relied on conventional digital subtraction angiography to identify stenosis, occlusions and aneurysms. The earliest detectable abnormality is usually the thickening of the vessel wall due to inflammation ${ }^{[10]}$. Conventional digital subtraction angiography has the least sensitivity for visualizing wall thickness. A systematic review showed the presence of a low attenuation ring in computed tomography (CT) angiogram as $100 \%$ specificity for disease activity ${ }^{[19]}$. Vessel wall thickening with enhancement had a sensitivity of $88 \%$ and specificity of $75 \%$. MRI is highly accurate and sensitive, 
Table 2. Merits and limitations of different imaging modalities to assess Takayasu arteritis

\begin{tabular}{|c|c|c|}
\hline & Merits & Limitations \\
\hline $\begin{array}{l}\text { Conventional digital } \\
\text { subtraction angiography }\end{array}$ & $\begin{array}{l}\text { Evaluation of severity of stenotic lesions } \\
\text { Assment of central blood pressure } \\
\text { Concomitant therapeutic intervention as necessary }\end{array}$ & $\begin{array}{l}\text { Invasive } \\
\text { Risk of contrast induced nephropathy } \\
\text { Radiation } \\
\text { Inablity to assess the thickness of arterial } \\
\text { wall }\end{array}$ \\
\hline CT angiography & $\begin{array}{l}\text { Ability to evaluate stenotic and aneurysmal lesions } \\
\text { Ability to measure arterial wall thickness } \\
\text { When used in patients at high suspicion for TA, CTA has a } \\
\text { sensitivity of } 95 \% \text { and specificity of } 100 \% \text {, using catheter- } \\
\text { based angiography as the gold standard }\end{array}$ & $\begin{array}{l}\text { Risk of contrast induced nephropathy } \\
\text { Radiation }\end{array}$ \\
\hline Magnetic resonance imaging & $\begin{array}{l}\text { Ability to evaluate stenotic and aneurysmal lesions Vessel } \\
\text { wall evaluation (thickening, oedema, degeneration) } \\
\text { Better assement of soft tissue when comapred to CTA No } \\
\text { radiation exposureSensitivity and specificity of } 100 \% \text { vs } \\
\text { catheter-based angiography }\end{array}$ & $\begin{array}{l}\text { Decreased sensitivity for smaller branch } \\
\text { involvement } \\
\text { Overestimate degrees of severe stenosis or } \\
\text { occlusion }\end{array}$ \\
\hline $\begin{array}{l}\text { 18F-fluorodeoxyglucose } \\
\text { positron emission } \\
\text { tomography (FDG-PET) }\end{array}$ & $\begin{array}{l}\text { Localise active inflammation and intensity of inflammation } \\
\text { Sensitivity and specificity } 70.1 \% \text { and } 77.2 \% \text { for evaluation } \\
\text { of disease activity }\end{array}$ & Not an angiographic study modality \\
\hline Duplex ultrasound & $\begin{array}{l}\text { Ability to evaluate localised areas of stenosis and } \\
\text { aneurysm } \\
\text { Non-invasive } \\
\text { No radiation exposure } \\
\text { Nocontrast }\end{array}$ & $\begin{array}{l}\text { Unable to provide a "roadmap" of vascular } \\
\text { lesions } \\
\text { Unable to perform complete imaging of the } \\
\text { aortic arch and descending aorta } \\
\text { Operator dependent }\end{array}$ \\
\hline $\begin{array}{l}\text { Ansthoracic and } \\
\text { transesophageal } \\
\text { echocardiography }\end{array}$ & $\begin{array}{l}\text { Non-invasive } \\
\text { Ability for concomitant assessment of aortic root and } \\
\text { aortic valve for insufficiency } \\
\text { Can be used for surveillance of ascending aorta dilatation, } \\
\text { detection of PHT, and possibly aortic wall thickening }\end{array}$ & $\begin{array}{l}\text { Unable to provide a 'roadmap' of vascular } \\
\text { lesions } \\
\text { Unable to differentiate among pathologies } \\
\text { causing hypo echoic aortic wall mural } \\
\text { thickening } \\
\text { Operator dependent }\end{array}$ \\
\hline
\end{tabular}

CT: computed tomography; CTA: CT angiography; TA: Takayasu's arteritis; PHT: pulmonary hypertension

and has the potential to assess disease activity and response to treatment ${ }^{[10]}$. FDG-PET is an operatorindependent, non-invasive metabolic imaging tool helpful in diagnosis of TA. It has a high sensitivity and specificity, which increases the overall efficacy of the modality in diagnosis.

\section{General consideration in surgery}

The disease goes through three phases - pre-pulseless, pulseless and burnt out. This may be an oversimplification of the complex disease process, and not all patients follow this outline. The few general principles that physicians should keep in mind when treating such patients are as follows ${ }^{[20-23]}$ : (1) usually an emergency surgery is not required as the stenotic lesions are well collateralized; (2) it is preferred to avoid surgery during the active phase. If required, suppress the active disease with medication before considering surgery; (3) TA patients are often on steroid therapy, making them high-risk surgical candidates due to effects of medications - for obesity, immunosuppression, bleeding diathesis; and (4) the disease is progressive, and hence, the patient should be on constant surveillance with medication. It is not uncommon to see complications such as restenosis, graft occlusion, graft site aneurysm and pseudoaneurysm due to the progressive nature of the disease.

The incidence of all the disease is shown in Table $3^{[6,24,25]}$.

\section{CORONARY ARTERY DISEASE}

Coronary artery disease (CAD) in TA was first described by Frovig and Loken in 1951, and Coronary artery bypass grafting (CABG) was first performed by Young and colleagues in 1973. Coronary angiographic and pathologic studies together have revealed coronary artery lesions in 9 to $11 \%$ of cases ${ }^{[21]}$. CAD in TA is usually associated with lesions of peripheral branch arteries, and isolated CAD is present in less than $5 \%$ of patients ${ }^{[26-28]}$. 
Table 3. Incidence of cardiovascular manifestation in Takasyu's arteritis

\begin{tabular}{ll}
\hline & \multicolumn{1}{c}{ Incidence } \\
\hline Hypertension & $34 \%-79.2 \%$ \\
Pulmonary arteritis & $7.1 \%-18.9 \%$ \\
Coronary artery disease & $5.20 \%-20.1 \%$ \\
Ischemic heart diseae & $10.60 \%$ \\
Myocardial failure & $6.60 \%$ \\
Aortic regurgitation & $33.20 \%-38.80 \%$ \\
Aortic aneurysm & $15.00 \%-23.30 \%$ \\
\hline
\end{tabular}

\section{Classification}

The coronary lesions are classified into 3 types: (1) Type I: stenotic lesion in the ostial segment of the coronary artery. This is the most commonly encountered type in clinical practice; (2) type II: diffuse involvement of the coronary arteries or any focal segment of the artery - skip lesions; and (3) type III: aneurysm of the coronary artery.

\section{Pathogenesis}

Active inflammation leads to intimal proliferation and fibrous contraction in the region around the coronary ostium leading to the narrowing of the coronary artery. Ischemia is one of the major causes of death in TA patients. Though extremely difficult, a high degree of suspicion is necessary to diagnosis these patients in the pre-stenotic phase. In patients with diminished/absent pulse, it may take several months/ years, before the coronary artery becomes involved. In a study from Korea, where CT aortogram was performed in 111 patients, there was a high prevalence of coronary artery abnormalities on coronary CT angiography, regardless of disease activity or symptoms. Hence, it was recommended to perform coronary CT angiography in all patients with TA for additional information ${ }^{[29]}$.

\section{Management}

Patients on conservative management have a grave prognosis with many dying of cardiac events ${ }^{[30]}$. Revascularisation should be considered as early as possible. It is advisable to avoid surgery in the active phase; however, to avoid any cardiac accidents, revascularisation has to be performed in unstable patients. In such patients, corticosteroid (CS) or immunosuppressive therapy should be administered at the same time to control the inflammatory process ${ }^{[31]}$. Biologic therapy, with namely anti-IL-6 (tocilizumab, TCZ) and TNFi (etanercept, infliximab and adalimumab), has been evaluated in TA. Improvement in disease activity was observed, and TA patients were able to taper or discontinue CSs after initiation of TCZ or TNFi. Even though there was clinical efficacy, radiological progression was the concern in TA patients on TCZ. There is evidence favoring the use of TCZ and TNFi in refractory and relapsing TA not responding to csDMARDs (conventional DMARDs). Abatacept (CTLA4-Ig) use in TA did not meet the primary endpoints in randomized controlled trials (RCTs). Rituximab (anti-CD 20) and ustekinumab (anti-IL-12/23) in TA gave variable results in isolated case reports ${ }^{[32-34]}$. High-dose prednisolone $(1 \mathrm{mg} / \mathrm{kg} / \mathrm{day})$ or its equivalent is the initial therapy for active TA with tapering dose for 3 to 6 months. CS dose of $0.5 \mathrm{mg} / \mathrm{kg} / \mathrm{day}$ together with immunosuppressive agent such as mycophenolate has been recently suggested with equal early response. Tapering of steroids can be started in 4 to 6 weeks ${ }^{[34]}$. Doses below $10 \mathrm{mg} /$ day are associated with increased relaps $\mathrm{e}^{[34]}$. Conventional immunosuppressive agents are started simultaneously with CS or while tapering it. There are no RCTs on the use of conventional synthetic disease-modifying antirheumatic drugs for TA. Weekly methotrexate (15-25 mg/week) therapy has been the first option by many physicians because of low cost and easy availability. AZA (azathioprine) at $2 \mathrm{mg} / \mathrm{kg} /$ day along with CSs for a period of 12 months showed reduction in inflammatory markers with no radiological progression. Severe TA (retinal vasculitis, severe AR, myocarditis, or pulmonary vasculitis with or without aneurysm) cases were given oral cyclophosphamide at $2 \mathrm{mg} / \mathrm{kg} /$ day. Mycophenolate mofetil has been a safe and effective drug at a dose of $2 \mathrm{~g} /$ day in treating TA. Both clinical and radiological progression was prevented when given for 
at least a period of one year. Leflunomide ( $20 \mathrm{mg} /$ day), tacrolimus and cyclosporine A have been tried with favourable outcome ${ }^{[33-36]}$. Vascular interventional procedures are better to be done during the inactive phase of the disease with perioperative continuation of immunosuppression for desired results ${ }^{[34]}$. Preoperative course of steroids might reduce the vasculitic activity ${ }^{[36]}$.

In has been suggested by some authors that in active TA, endoluminal stenting and rotational atherectomy can be used to postpone surgery ${ }^{[37]}$. Though long-term results do not favour percutaneous coronary intervention (PCI) for TA, PCI can be performed in an emergency situation, patients who refuse CABG or in high-risk individuals. With regard to MACE, CABG is superior to PCI despite medical therapy in TA patients with CAD.

A meta-analysis revealed that restenosis occurred more often with PCI than with open surgical intervention for coronary artery involvement ${ }^{[38]}$. On a cohort of 75 patients who underwent revascularisation, a recurrent restenosis was demonstrated in more than three-fourths (78\%) of angioplasties and 36\% of surgical procedures ${ }^{[16]}$. Very little exists in the literature with regard to PCI for CAD in TA patients, barring a few anecdotal case reports and small case series. Vasculitis, accelerated atherosclerosis and blood flow alteration due to structural changes in vessel wall lead to acute ischemic events in TA. TXB2 (thromboxane B2) level and platelet aggregation is increased in patients with TA. Low doses of aspirin are safe and useful in preventing acute events of ischemia in TA. Antiplatelet therapy in pre- and post-endovascular procedures reduce restenosis occurrence in $\mathrm{TA}^{[33,39]}$.

\section{Surgery in CAD}

In contrast to atherosclerotic disease, the use of the internal mammary artery raises concerns even though the TA patients are young. A study of 321 TA patients in Japan showed that the most common involved artery was the left subclavian followed by the carotid artery and right subclavian ${ }^{[40]}$. Thus, the long-term benefit of using the internal mammary artery as a conduit rings a bell, while on the other hand, the use of saphenous vein graft has been recommended ${ }^{[41]}$. In a review by Amano and Suzuki, saphenous vein grafts were used in $80 \%$ of patients ${ }^{[31]}$. As TA is a progressive disease, there is intimal proliferation which can cause stenosis of the proximal anastomosis of the vein graft on the ascending aorta. Few authors have suggested replacing a segment of ascending aorta with a Dacron patch, to which the proximal anastomosis of the vein graft can be performed instead of the native aorta ${ }^{[41]}$. Though long-term results are unknown, few authors have suggested the use of the free internal mammary artery and radial artery ${ }^{[42,43]}$. Late coronary artery bypass grafting was insufficient in $10 \%$ of patients undergoing surgery ${ }^{[6]}$.

Other options for coronary interventions are surgical angioplasty of the left main coronary artery and transaortic coronary ostial endarterectomy ${ }^{[4]}$. Surgical angioplasty can be performed using a piece of autologous pericardium, glutaraldehyde-treated pericardium, saphenous vein graft or a patch from the internal mammary artery. Transaortic coronary ostial endarterectomy was indicated in patients with localized lesions at the coronary ostium. The stenotic portion of the coronary artery is held with a piece of thread and resected piecemeal with a scalpel and later punched out with a 4-mm Aorta-Punch. Care has to be taken, as excessive resection may lead to perforation, bleeding, or hematoma at the junction of the aorta and the ostium of the coronary artery.

\section{MYOCARDIUM IN TA}

Myocardial failure in TA can be due to systemic arterial involvement, hypertension, acute or chronic AR, and pulmonary vascular involvement in patients with $\mathrm{TA}^{[45]}$. It was demonstrated that the natural killer cells and T lymphocyte-mediated autoimmune cell injury can happen by releasing the cytotoxic factor and perforin in the vessel wall ${ }^{[46]}$. Takeda et al ${ }^{[47]}$ postulated a similar mechanism of myocardial involvement in certain patients with TA. An immunohistochemical study of the cardiac myocytes was also positive for 
HLA classes I and II, and ICAM-1, indicating the involvement of an active inflammatory process ${ }^{[48]}$. A study of 204 Korean patients showed elevated NT-proBNP in active TA. The possible reasons for the rise could have been due to elevated filling pressure of the ventricles, pulmonary arterial hypertension, left ventricular failure and/or AR in these patients ${ }^{[49]}$.

\section{PULMONARY ARTERITIS}

Pulmonary arteritis (PA) involvement in TA is not uncommon. The incidence of PA in patients with TA varies greatly in the literature $(0-56 \%)^{[50,51]}$. Pulmonary hypertension occurs in $12 \%$ to $13 \%$ of patients with TA and in $42.2 \%$ of patients with $\mathrm{PA}^{[51,52]}$. As the patients present with non-specific respiratory symptoms and lack of vessel involvement, the diagnosis is usually delayed in these patients. PA manifests as pulmonary hypertension, which indicates a weak response to treatment and carries a poor prognosis ${ }^{[52]}$. The median time from the initial symptoms to definitive diagnosis is 13.5 (1-186) months ${ }^{[53]}$. High-dose glucocorticoid remains the standard of care and a combination of glucocorticoid and methotrexate or azathioprine prolongs disease remission. Few case reports of successful pulmonary artery revascularisations exist in the literature, but they are reserved for renal vascular hypertension, extremity claudication or cerebral vascular disease ${ }^{[52]}$.

\section{AORTIC VALVE AND AORTIC ROOT}

A study of 1,069 patients from China showed that more than one-third (34.9\%) of the TA patients had cardiac valve involvement ${ }^{[24]}$. Regurgitation lesions are more common than stenosis, with AR being the commonest lesion in TA patients. AR in TA was first described by Jervell in $1954^{[54]}$. The incidence of AR ranges from $20.0 \%$ to $44.8 \%$ in different populations ${ }^{[17,55,56]}$.

\section{Pathogenesis}

It is believed that inflammation rarely involves the aortic valve and that AR develops primarily as a result of annular dilatation. The $\mathrm{T}$ lymphocytes and macrophages after infiltration, initiate an immunologic cascade in the aortic wall. This causes release of cytokines and matrix metalloproteinases, destroying the aortic wall ${ }^{[57-59]}$. The inflammation involves the aortic wall from the adventitia to intima, damaging the media. This will make the aortic root fragile, which in turn is unable to bear the stress and start to dilate ${ }^{[24]}$. The secondary AR jet induces morphological changes in the aortic valve leaflets such as fibrous thickening and enrolling and thereby worsens the AR itself.

\section{Management}

Chronic AR leads to heart failure, which is the main cause of death in patients with $\mathrm{TA}^{[24]}$. Hence, the presence of AR necessitates early surgery before decompensating. However, surgical treatment of AR in TA is difficult because of the need to manipulate fragile and inflamed tissue. The disease actively has to be monitored as mentioned earlier. When examining a patient with AR, the physician should be aware of the common differential diagnosis in valvular heart disease- rheumatic heart disease, degenerative valvular heart. Echocardiogram should identify the pathology of the valve and establish the diagnosis.

Patients who undergo surgery are prone to prosthetic valve detachment, paravalvular leak or pseudoaneurysm at the anastomotic site. The incidence of postoperative anastomotic aneurysm has been reported to be $8.5 \%-13.8 \%$, while that of the prosthetic valve detachment has been reported as $4 \%-25 \%$ in different series ${ }^{[60]}$. Miyata et al. ${ }^{[61]}$ reported that occurrence of anastomotic aneurysm was not related to the presence of inflammation, preoperative use of steroids, or pathological stage. This anastomotic aneurysm could develop any time after the operation, and hence, the patients require alifelong surveillance. There are concerns about the dilatation of the ascending aorta after aortic valve replacement alone. Bougioukas et al. ${ }^{[62]}$ proposed avoiding valve-sparing aortic root replacement in TA patients, as there is a high incidence of 
recurrent regurgitation. Matsuura et al.$^{[63]}$ reported that the outcomes of aortic valve replacement (AVR) are comparable to aortic root replacement, though late dilatation of the residual ascending aorta is the major concern in long-term follow-up for patients with AVR. Redo-AVR was done in three-fourths of patients who underwent valve sparing aortic root replacement within 3 years of follow-up after the operation. Considering these facts, it is advisable to do an aortic root replacement for TA patients than to consider an AVR or David's procedure. Aortic root replacement can safely be performed and shows a higher event-free ratio when compared to AVR alone in $\mathrm{TA}^{[47,63,64]}$.

\section{CONCLUSION}

TA is a rare with a challenging course of disease process. Since the incidence is low, there are no formal guidelines for treatment of these patients. Considering the facts, the treatment has to be individualised to patients. It is preferred to avoid surgery in the active phase, and if required, disease activity can be controlled with medications and surgery. Long-term surveillance is required for all these patients as they are prone to complications.

\section{DECLARATIONS}

\section{Authors' contributions}

Contributed equally to the conception, data collection and writing of the manuscript: Idhrees M, Thilagavathi N, Bashir M, Velayudhan BV

\section{Availability of data and materials}

Not applicable.

\section{Financial support and sponsorship}

None.

\section{Conflicts of interest}

All authors declared that there are no conflicts of interest.

\section{Ethical approval and consent to participate}

Not applicable.

\section{Consent for publication}

Not applicable.

\section{Copyright}

(c) The Author(s) 2020.

\section{REFERENCES}

1. Zaldivar Villon MLF, de la Rocha JAL, Espinoza LR. Takayasu arteritis: recent developments. Curr Rheumatol Rep 2019;21:45.

2. Seyahi E. Takayasu arteritis: an update. Curr Opin Rheumatol 2017;29:51-6.

3. Mohammad AJ, Mandl T. Takayasu arteritis in southern Sweden. J Rheumatol 2015;42:853-8.

4. Gudbrandsson B, Molberg Ø, Garen T, Palm Ø. Prevalence, incidence, and disease characteristics of Takayasu arteritis by ethnic background: data from a large, population-based cohort resident in Southern Norway. Arthritis Care Res (Hoboken) 2017;69:278-85.

5. Watanabe Y, Miyata T, Tanemoto K. Current clinical features of new patients with Takayasu arteritis observed from cross-country research in Japan: age and sex specificity. Circulation 2015;132:1701-9.

6. Isobe M, Amano K, Arimura Y, Ishizu A, Ito S, et al. JCS 2017 Guideline on Management of Vasculitis Syndrome - Digest Version. Circ J 2020;84:299-359.

7. Renauer P, Sawalha AH. The genetics of Takayasu arteritis. Presse Med 2017;46:e179-87.

8. Facchinetti M, Pierantonio Ostuni \& Gabriella Cardinale. A familial case of Takayasu arteritis: HLA-related genetic susceptibility and 
efficacy of anti-TNF $\alpha$ treatment in two Italian siblings. Int J Clin Rheumatol 2018;13:341-5.

9. Chatterjee S, Flamm SD, Tan CD, Rodriguez ER. Clinical diagnosis and management of large vessel vasculitis: Takayasu arteritis. Curr Cardiol Rep 2014;16:499.

10. Alibaz-Oner F, Aydin SZ, Direskeneli H. Advances in the diagnosis, assessment and outcome of Takayasu's arteritis. Clin Rheumatol 2013;32:541-6.

11. Devarasetti PK, Irlapati RV, Rajasekhar L. Pentraxin 3 is better than conventional inflammatory markers for disease activity assessment in Takayasu arteritis. Indian J Rheumatol 2019;14:21-7.

12. Devarasetti PK, Appani SK, Irlapati RVP, Rajasekhar L. SAT0364 pentraxin 3 as biomarker in assessment of disease activity in Takayasu arteritis. Ann Rheum Dis 2016;75:798.

13. Direskeneli H, Aydin SZ, Merkel PA. Assessment of disease activity and progression in Takayasu's arteritis. Clin Exp Rheumatol 2011;29:S86-91.

14. Nair AM, Goel R, Hindhumati M, Jayakanthan K, Visalakshi J, et al. Serum amyloid A as a marker of disease activity and treatment response in Takayasu arteritis. Rheumatol Int 2017;37:1643-9.

15. Goel R, Kabeerdoss J, Mohan H, Danda S, Jayaseelan V, et al. Soluble-HLA-E: a follow up biomarker in Takayasu arteritis, independent of HLA-E genotype. Int J Rheum Dis 2018;21:532-40.

16. Maksimowicz-McKinnon K, Clark TM, Hoffman GS. Limitations of therapy and a guarded prognosis in an American cohort of Takayasu arteritis patients. Arthritis Rheum 2007;56:1000-9.

17. Kerr GS, Hallahan CW, Giordano J, Leavitt RY, Fauci AS, et al. Takayasu arteritis. Ann Intern Med 1994;120:919-29.

18. Kim ESH, Beckman J. Takayasu arteritis: challenges in diagnosis and management. Heart 2018;104:558-65.

19. Barra L, Kanji T, Malette J, Pagnoux C; CanVasc. Imaging modalities for the diagnosis and disease activity assessment of Takayasu's arteritis: a systematic review and meta-analysis. Autoimmun Rev 2018;17:175-87.

20. Miyata T, Sato O, Koyama H, Shigematsu H, Tada Y. Long-term survival after surgical treatment of patients with Takayasu's arteritis. Circulation 2003;108:1474-80.

21. Isobe M. Takayasu arteritis revisited: current diagnosis and treatment. Int J Cardiol 2013;168:3-10.

22. Ogino H, Matsuda H, Minatoya K, Sasaki H, Tanaka H, et al. Overview of late outcome of medical and surgical treatment for Takayasu arteritis. Circulation 2008;118:2738-47.

23. Fields CE, Bower TC, Cooper LT, Hoskin T, Noel AA, et al. Takayasu's arteritis: operative results and influence of disease activity. J Vasc Surg 2006;43:64-71.

24. Zhang Y, Yang K, Meng X, Tian T, Fan P, et al. Cardiac valve involvement in Takayasu arteritis is common: a retrospective study of 1,069 patients over 25 years. Am J Med Sci 2018;356:357-64.

25. Goel R, Gribbons KB, Carette S, Cuthbertson D, Hoffman GS, et al. Derivation of an angiographically based classification system in Takayasu's arteritis: an observational study from India and North America. Rheumatology (Oxford) 2020;59:1118-27.

26. Kihara M, Kimura K, Yakuwa H, Minamisawa K, Hayashi S, et al. Isolated left coronary ostial stenosis as the sole arterial involvement in Takayasu's disease. J Intern Med 1992;232:353-5.

27. Lanjewar C, Kerkar P, Vaideeswar P, Pandit S. Isolated bilateral coronary ostial stenosis - an uncommon presentation of aortoarteritis. Int J Cardiol 2007;114:e126-8.

28. Lie JT. Pathology of isolated nonclassical and catastrophic manifestations of Takayasu arteritis. Int J Cardiol 1998;66 Suppl 1:S11-21.

29. Kang EJ, Kim SM, Choe YH, Lee GY, Lee KN, et al. Takayasu arteritis: assessment of coronary arterial abnormalities with 128-section dual-source CT angiography of the coronary arteries and aorta. Radiology 2014;270:74-8.

30. Cipriano PR, Silverman JF, Perlroth MG, Griepp RB, Wexler L. Coronary arterial narrowing in Takayasu's aortitis. Am J Cardiol 1977;39:744-50.

31. Amano J, Suzuki A. Coronary artery involvement in Takayasu's arteritis. Collective review and guideline for surgical treatment. J Thorac Cardiovasc Surg 1991;102:554-60.

32. Águeda AF, Monti S, Luqmani RA, Buttgereit F, Cid M, et al. Management of Takayasu arteritis: a systematic literature review informing the 2018 update of the EULAR recommendation for the management of large vessel vasculitis. RMD Open 2019;5:e01020.

33. Keser G, Direskeneli H, Aksu K. Management of Takayasu arteritis: a systematic review. Rheumatology 2014;53:793-801.

34. Misra DP, Wakhlu A, Agarwal V, Danda D. Recent advances in the management of Takayasu arteritis. Int J Rheum Dis 2019;22 Suppl $1: 60-8$.

35. Tombetti E, Manfredi A, Sabbadini MG, Baldissera E. Management options for Takayasu arteritis. Expert Opin Orphan Drugs 2013;1:685-93.

36. Weaver FA, Yellin AE, Campen DH, Oberg J, Foran J, et al. Surgical procedures in the management of Takayasu's arteritis. J Vasc Surg 1990;12:429-39.

37. Son JW, Koh KK, Dang Q, Choi IS, Shin EK. Recurrent restenosis following stent and rotational atherectomy of coronary artery stenosis in Takayasu's arteritis. Int J Cardiol 1998;65:295-300.

38. Jung JH, Lee YH, Song GG, Jeong HS, Kim JH, et al. Endovascular versus open surgical intervention in patients with Takayasu's arteritis: a meta-analysis. Eur J Vasc Endovasc Surg 2018;55:888-99.

39. Ueno M. Antiplatelet therapy in the treatment of Takayasu arteritis. Circ J 2010;74:1079-80.

40. Ueda H, Ito I, Saito Y. Studies on arteritis, with special reference to pulseless disease and its diagnosis. Naika 1965;15:239-56.

41. Yang Y, Tian T, Yang K, Zhang Y, Meng X, et al. Outcomes of percutaneous coronary intervention and coronary artery bypass grafting in patients with Takayasu arteritis. Int J Cardiol 2017;241:64-9. 
42. Emaminia A, Amirghofran AA. Complete occlusion of the left main coronary artery ostium in Takayasu arteritis. J Thorac Cardiovasc Surg 2008;135:695-6.

43. Yuan SM, Lin HZ. Coronary artery involvements in Takayasu arteritis: systematic review of reports. Gen Thorac Cardiovasc Surg 2020; doi:10.1007/s11748-020-01378-3.

44. Endo M, Tomizawa Y, Nishida H, Aomi S, Nakazawa M, et al. Angiographic findings and surgical treatments of coronary artery involvement in Takayasu arteritis. J Thorac Cardiovasc Surg 2003;125:570-7.

45. Lupi-Herrera E, Sanchez-Torres G, Marcushamer J, Mispireta J, Horwitz S, et al. Takayasu's arteritis. Clinical study of 107 cases. Am Heart J 1977;93:94-103.

46. Seko Y, Minota S, Kawasaki A, Shinkai Y, Maeda K, et al. Perforin-secreting killer cell infiltration and expression of a 65-kD heat-shock protein in aortic tissue of patients with Takayasu's arteritis. J Clin Invest 1994;93:750-8.

47. Takeda N, Takahashi T, Seko Y, Maemura K, Nakasone H, et al. Takayasu myocarditis mediated by cytotoxic T lymphocytes. Intern Med 2005;44:256-60.

48. Noel N, Butel N, Le Hoang P, Koskas F, Costedoat-Chalumeau N, et al. Small vessel involvement in Takayasu's arteritis. Autoimmun Rev 2013;12:355-62.

49. Lee GY, Jang SY, Ko SM, Kim EK, Lee SH, et al. Cardiovascular manifestations of Takayasu arteritis and their relationship to the disease activity: analysis of 204 Korean patients at a single center. Int J Cardiol 2012;159:14-20.

50. Hotchi M. Pathological studies on Takayasu arteritis. Heart Vessels Suppl 1992;7:11-7.

51. Sharma BK, Jain S, Radotra BD. An autopsy study of Takayasu arteritis in India. Int J Cardiol 1998;66:S85-90.

52. Toledano K, Guralnik L, Lorber A, Ofer A, Yigla M, et al. Pulmonary arteries involvement in Takayasu's arteritis: two cases and literature review. Semin Arthritis Rheum 2011;41:461-70.

53. Yang J, Peng M, Shi J, Zheng W, Yu X. Pulmonary artery involvement in Takayasu's arteritis: diagnosis before pulmonary hypertension. BMC Pulm Med 2019;19:225.

54. Jervell A. Pulseless disease. Am Heart J 1954;47:780-4.

55. Soto ME, Espinola-Zavaleta N, Ramirez-Quito O, Reyes PA. Echocardiographic follow-up of patients with Takayasu's arteritis: five-year survival. Echocardiography 2006;23:353-60.

56. Yoshida M, Watanabe R, Ishii T, Machiyama T, Akita K, et al. Retrospective analysis of 95 patients with large vessel vasculitis: a single center experience. Int J Rheum Dis 2016;19:87-94.

57. Luo F, Zhou XL, Li JJ, Hui RT. Inflammatory response is associated with aortic dissection. Ageing Res Rev 2009;8:31-5.

58. Shirai T, Hilhorst M, Harrison DG, Goronzy JJ, Weyand CM. Macrophages in vascular inflammation--from atherosclerosis to vasculitis. Autoimmunity 2015;48:139-51.

59. Wang Y, Wu B, Dong L, Wang C, Wang X, et al. Circulating matrix metalloproteinase patterns in association with aortic dilatation in bicuspid aortic valve patients with isolated severe aortic stenosis. Heart Vessels 2016;31:189-97.

60. Kaku Y, Aomi S, Tomioka H, Yamazaki K. Surgery for aortic regurgitation and aortic root dilatation in Takayasu arteritis. Asian Cardiovasc Thorac Ann 2015;23:901-6.

61. Miyata T, Sato O, Deguchi J, Kimura H, Namba T, et al. Anastomotic aneurysms after surgical treatment of Takayasu's arteritis: a 40-year experience. J Vasc Surg 1998;27:438-45.

62. Bougioukas I, Mikroulis D, Popov AF, Bougioukas G. Re-do aortic operation in a young patient for aggressive Takayasu's arteritis. J Cardiothorac Surg 2012;7:9.

63. Matsuura K, Ogino H, Kobayashi J, Ishibashi-Ueda H, Matsuda H, et al. Surgical treatment of aortic regurgitation due to Takayasu arteritis: long-term morbidity and mortality. Circulation 2005;112:3707-12.

64. Adachi O, Saiki Y, Akasaka J, Oda K, Iguchi A, et al. Surgical management of aortic regurgitation associated with Takayasu arteritis and other forms of aortitis. Ann Thorac Surg 2007;84:1950-4. 